\title{
An Experimental Investigation the Optimum of Salinity and Ph of Sea-Water to Improve Oil Recovery from Sandstone Reservoir as A Secondary Recovery Process
}

\author{
Madi Abdullah Naser ${ }^{1 *)}$, Mohammed A Samba ${ }^{2)}$, Yiqiang $\mathrm{Li}^{3 \text { ) }}$ \\ 1) Petroleum Engineering, Faculty of Engineering, Misrata University-Libya \\ 2) Petroleum Engineering, Faculty of Engineering, China University of Petroleum-Beijing \\ 3) Petroleum Engineering, Faculty of Engineering, China University of Petroleum-Beijing \\ * corresponding email: m.naser@eng.misuratau.edu.ly
}

\begin{abstract}
Laboratory tests and field applications shows that the salinity of water flooding could lead to significant reduction of residual oil saturation. There has been a growing interest with an increasing number of low-salinity water flooding studies. However, there are few quantitative studies on seawater composition change and it impact on increasing or improving oil recovery. This study was conducted to investigate only two parameters of the seawater (Salinity and $\mathrm{pH})$ to check their impact on oil recovery, and what is the optimum amount of salinity and ph that we can use to get the maximum oil recovery. Several core flooding experiments were conducted using sandstone by inject seawater (high, low salinity and different $\mathrm{pH}$ ). The results of this study has been shown that the oil recovery increases as the injected water salinity down to $6500 \mathrm{ppm}$ and when the $\mathrm{pH}$ is around 7. This increase has been found to be supported by an increase in the permeability. We also noticed that the impact of ph on oil recovery is low when the $\mathrm{pH}$ is less than 7.
\end{abstract}

Keywords: impact of salinity and ph on oil recovery; oil recovery improvement; sandstone reservoir; seawater injection; secondary recovery

\section{INTRODUCTION}

Water injection is the most familiar used for secondary recovery because it is cheap. Water is cheap and usually available in large volumes. Up to present, the mobility ratio of the oil and water, water composition and the heterogeneity of the reservoir are the key factors to success any water flooding project (Elsharafi, 2018) (Brian, 2007). Modification of the water composition has shown to be an excellent way to increase recovery from both sandstone and carbonates. Many researchers have reported both in field and in laboratory test, increasing in oil recovery by Modified of the water composition (Tang \& Morrow, 1996).

Recent laboratory and field observations have indicated that oil recovery increases when usual sea-water injection in conventional water flooding is replaced with the injection of low salinity brines. Where the first studies of low salinity water to improve oil recovery were published on 1959, which was concerning about the salinity in clay swelling, and consequent on oil recovery in water flooding (Hughes \& Pfister, 1947). They also observed increased oil recovery with decrease in injection brine salinity during water flooding. However, not always the low salinity increases the oil recovery as has mentioned in some reporters (Sharma \& Filoco, 2000). (Sharma \& Filoco, 2000) have observed no improved oil recovery by reducing injection brine salinity but reported an increase in oil recovery only when the connate water salinity was reduced. They attributed the increased recovery to the wettability alteration to a mixed wet condition.

According to (Appelo, 1994) the injection of fresh water in a saline aquifer is accompanied by a loss of $\mathrm{Na}_{+}$and $\mathrm{Mg}_{2}+$ from the exchanger and an increase in $\mathrm{Ca}_{2}+$ at the exchanger surface. In principle the loss of $\mathrm{Ca}_{2}+$ from solution is sufficient to drive the dissolution reaction which should increase the $\mathrm{pH}$ up to 10 . However, this is not observed in an aquifer due to proton buffering, which will keep $\mathrm{pH}$ at about 7 to 8 . Proton buffering is due to the desorption of proton $\left(\mathrm{H}^{+}\right)$from oxides and organic matter. It is also due to the desorption of complexes, in combination with reactions from oxides (Griffioen, 1993).

Recent experimental data have shown that the resulting increase in $\mathrm{pH}$ as the low salinity brine displaces the high salinity formation water appeared to correspond to an increase in water wetness of initial mixed wet rock. An increase in $\mathrm{pH}$ will lead to a desorption of surface active organic components (acidic $\mathrm{RCOOH}$, and basic $\mathrm{R}^{\mathrm{N}} \mathrm{NH}^{+}$) from the clay minerals, which renders the rock more water wet (Madsen \& Ida, 1998; Romanuka et al., 2012). The increase in water wetness of initially by-passed pores will generate increased capillary forces, and the low salinity can then build up a new bank of oil by a spontaneous imbibition process. The low salinity has a lower viscosity than the high salinity brine, 
and therefore, the new bank of oil must be created due to an increase in capillary forces and not due to an increase in viscous forces. A chemical explanation of the wettability alteration mechanism by low salinity water has previously been proposed, (Austad et al., 2010; RezaeiDoust et al., 2011) and the chemical reactions for the process can be summarized in the following equations (Romanuka et al., 2012):

$$
\begin{aligned}
& \text { clay }-\mathrm{Ca}^{2+}+\mathrm{H}_{2} \mathrm{O}=\text { clay }-\mathrm{H}++\mathrm{OH}-+\mathrm{Ca}+\text { heat } \\
& \text { clay }-\mathrm{R}_{3} \mathrm{NH}^{+}+\mathrm{OH}^{-}=\text {clay }+\mathrm{R}_{3} \mathrm{~N}:+\mathrm{H}_{2} \mathrm{O} \\
& \text { clay }-\mathrm{RCOOH}+\mathrm{OH}^{-}=\text {clay }+\mathrm{RCOOH}^{-}+\mathrm{H}_{2}
\end{aligned}
$$

Cations such as $\mathrm{Ca}_{2}^{+}$, which are present in relatively large amounts in formation water $(\mathrm{FW})$ are desorbed from the clay surface in Equation 1, and are replaced by protons, $\mathrm{H}^{+}$, from the low salinity brine. This cation exchange results in a local increase in $\mathrm{pH}$ because of the $\mathrm{OH}^{-}$generated. In alkaline conditions the basic and acidic organic material are transformed to their least reactive state towards the clay, and are consequently detached from the clay surface, as shown in Equation 2 and Equation 3.

Also the connection between oil and clays from a chemistry perspective is described by (Lager et al., 2008). The authors conclude that the oil molecules are held on the surface of the negatively charged clay particles mainly by divalent cations. These are positively charged ions, such as calcium $\left(\mathrm{Ca}^{+}\right)$or magnesium $\left(\mathrm{Mg} 2^{+}\right)$, which act as tethers to hold the oil molecules onto the clay. When flooded with water that has a lower salinity than the reservoir formation water, free cations in the displacing fluid, for example monovalent sodium ions $\left(\mathrm{Na}^{+}\right)$, exchange with the divalent cations holding the oil in place and release the oil molecules, allowing these to be swept out of the rock pores. It has been observed that the more clay present in the reservoir, the greater will be the benefit of using low-salinity water (Jerauld et al., 2006). A basic schematic of this mechanism can be seen in Figure 1.
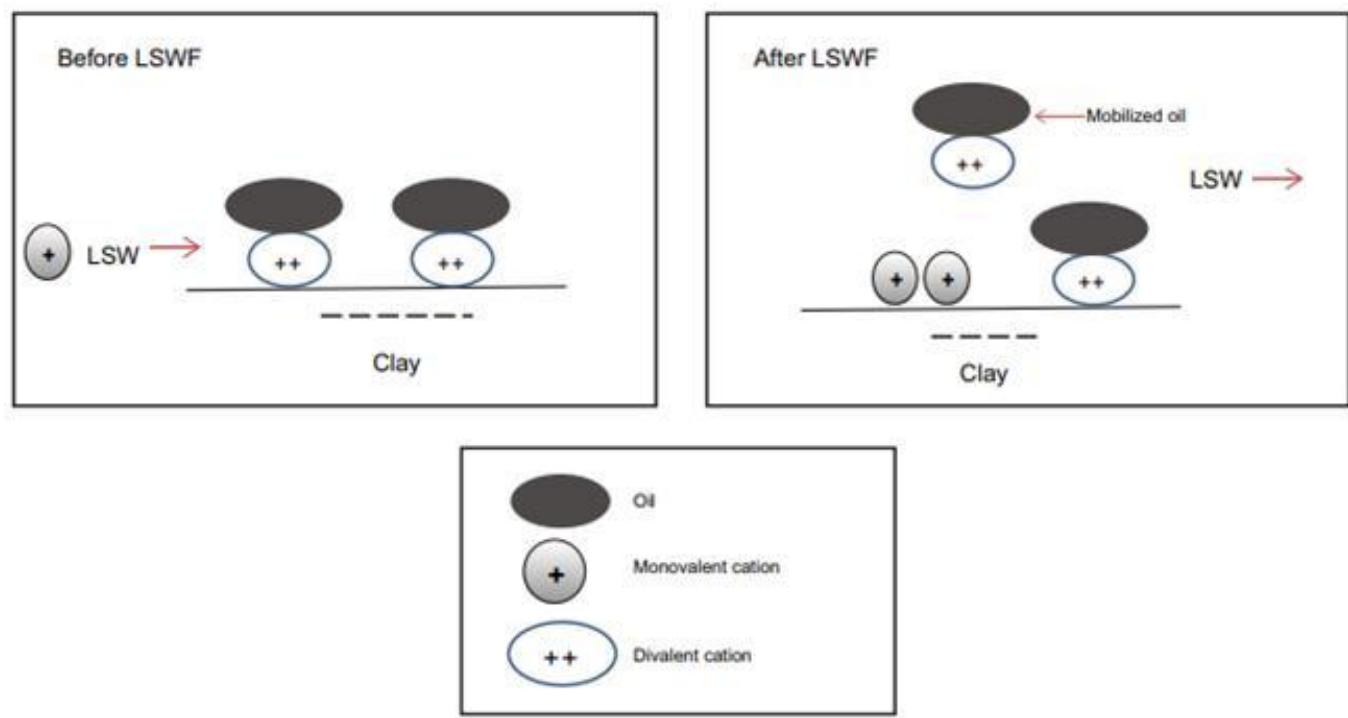

Figure 1. A Basic Schematic of Low Salinity Mechanism

Source: Jerauld et al., 2006

\section{MATERIALS}

The equipment's that have been used in this investigation experiment and their constructions are dean stark extractor, oven, Sartorius Precision balance, Manual saturator, liquidperm, PH meter, conductivity meter, DR 890 colorimeter, Heating device and Varner caliper. The other equipments have been used in this experiment are $100 \mathrm{ml}$ glass tube, $50 \mathrm{ml}$ glass tube, $500 \mathrm{ml}$ glass tube to fill it with oil and sink the samples into it in order to get them fully saturated with oil ,samples holder, chemical substances to adjust the seawater composition but in different lab, a temperature sensor to know the temperature around the liquidperm device, a timer to get the exact time for the experiment and especially to calculate the flow rate time, a calculator and a ruler, $50 \mathrm{ml}$ tubes with switched key on the bottom.

The materials used to conduct experiments in this work include sandstone cores, crude oil, sea water and distilled water. PH meter device have been used in this experiment to measure the ph of seawater, different PH has been modified by 
sodium hydroxide and $\mathrm{H}_{2} \mathrm{SO}_{4}$. the ph of seawater in this experiment was at 7.8, 10 to 13 and 4 . The salinity has been modified by use sodium chloride. The sea water analysis has been tested in Iron Steel Company laboratories to calculate the percentage of chloride $(\mathrm{Cl})$ magnesium $(\mathrm{Mg})$ and calcium $(\mathrm{Ca})$.

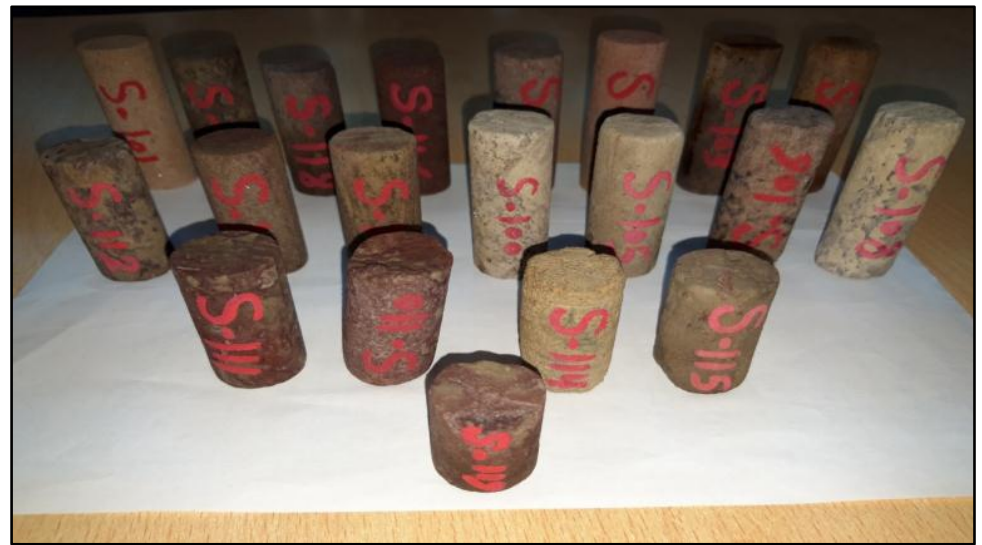

Figure 2. Shows the Sandstone Core Samples that Been Used In this Experiment

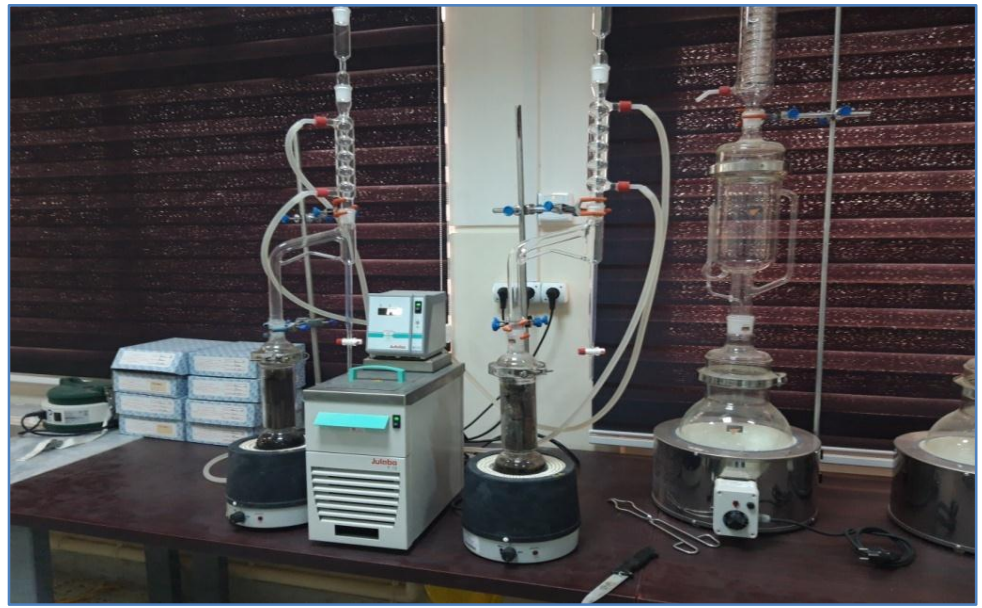

Figure 3. Shows the Flasks Full With Samples

\section{RESULTS}

\subsection{Seawater ph and Salinity Results}

The ph and salinity concentration change for all the cases, the original seawater ph measured by 3520 ph meter was 7.8 and the salinity by 4510 conductivity device was $21250 \mathrm{ppm}$ can be seen in Table 1.

Table 1. Seawater Samples with Different Concentration of $\mathrm{Ph}$ and Salinity

\begin{tabular}{cccccc}
\hline & $\begin{array}{c}\text { Case\#1 original } \\
\text { seawater }\end{array}$ & Case\#2 & Case\#3 & Case\#4 & Case\#5 \\
\hline PH & 7.8 & 7.8 & 7.8 & 9.98 & 4.4 \\
Salinity $(\mathrm{ppm})$ & 21250 & 14000 & 6500 & 21250 & 21250 \\
\hline
\end{tabular}

\subsection{Seawater Properties Results}

The results of two previous devices and DR890 colorimeter device and other chemical experiment results, Case\#1 and Case\#3 and 4 have the same properties because the change in ph has no big effect on composition can be seen in Table 2. 
Table 2. Results of Seawater Properties for All Cases

\begin{tabular}{ccccccccc}
\hline $\begin{array}{c}\text { Case } \\
\text { number }\end{array}$ & PH & $\begin{array}{c}\text { Conductivity } \\
\text { ppm }\end{array}$ & $\begin{array}{c}\text { T.D.S } \\
\text { PPM }\end{array}$ & $\begin{array}{c}\text { Ca } \\
\text { hardness } \\
\text { Ppm }\end{array}$ & $\begin{array}{c}\text { Mg } \\
\text { hardness } \\
\text { ppm }\end{array}$ & $\begin{array}{c}\text { Chloride } \\
\text { Ppm }\end{array}$ & $\begin{array}{c}\text { SO } \\
\text { mg/L }\end{array}$ \\
\hline 1 & 7.8 & 42500 & 21250 & 560 & 1296 & 2224 & 27 \\
2 & 7.8 & 28000 & 14000 & 250 & 1140 & 13578 & 80 \\
3 & 7.8 & 1300 & 6500 & 64 & 307.2 & 4544 & 80 \\
4 & 9.98 & 42500 & 21250 & 560 & 1296 & 2224 & 27 \\
5 & 4.4 & 42500 & 21250 & 560 & 1296 & 2224 & 27 \\
\hline
\end{tabular}

\subsection{Samples Dimensions Measurement Results}

The samples dimensions were measured by verner caliper, the dimensions were taken more than twice for accuracy, the dimensions are length, diameter. The dimensions of all samples that were taken in this research can be seen in Table 3.

Table 3. Samples Dimensions

\begin{tabular}{ccc}
\hline Sample Name & Diameter $(\mathbf{c m})$ & Length $(\mathbf{c m})$ \\
\hline S-100 & 2.492 & 7.2 \\
S-101 & 2.535 & 7.53 \\
S-102 & 2.488 & 7.705 \\
S-103 & 2.515 & 7.785 \\
S-104 & 2.497 & 6.345 \\
S-105 & 2.473 & 6.94 \\
S-106 & 2.468 & 7.035 \\
S-107 & 2.537 & 7.26 \\
S-108 & 2.45 & 7.415 \\
S-109 & 2.518 & 6.115 \\
S-110 & 2.53 & 5.59 \\
S-111 & 2.523 & 5.2 \\
S-112 & 2.498 & 5.785 \\
S-113 & 2.55 & 7.2 \\
S-114 & 2.51 & 4.85 \\
S-116 & 2.5 & 6.925 \\
S-117 & 2.5 & 7.955 \\
S-118 & 2.51 & 6.625 \\
S-119 & 2.35 & 3.455 \\
\hline
\end{tabular}

\subsection{Porosity Measurement by Manual Saturator}

Before determining porosity and after drying the samples by oven we have wieghted the samples by Sartorius balance device to see the difference after saturation.

The pore volume and bulk volume and the wieght of dried samples and porosity can be seen in Table 4 .

Table 4. Shows Bulk Volume Pore Volume And Pososity Results

\begin{tabular}{cccccccc}
\hline Sample & $\begin{array}{c}\text { Dry } \\
\text { Weight }\end{array}$ & $\begin{array}{c}\text { Weight } \\
\text { Saturation }\end{array}$ & $\begin{array}{c}\text { Diameter } \\
(\mathrm{cm})\end{array}$ & $\begin{array}{c}\text { Length } \\
(\mathrm{cm})\end{array}$ & $\begin{array}{c}\text { Bulk } \\
\text { Volume } \\
(\mathbf{m l})\end{array}$ & $\begin{array}{c}\text { Pore } \\
\text { Volume } \\
(\mathbf{m l})\end{array}$ & $\begin{array}{c}\text { Porosity } \\
\%\end{array}$ \\
\hline
\end{tabular}




\begin{tabular}{llcccccc}
\hline S-100 & 61.872 & 70.132 & 2.492 & 7.2 & 35.0993 & 8.26 & 23.5332 \\
S-101 & 69.191 & 79.166 & 2.535 & 7.53 & 37.9857 & 9.975 & 26.2599 \\
S-102 & 68.085 & 77.542 & 2.488 & 7.705 & 37.4406 & 9.457 & 25.2587 \\
S-103 & 73.356 & 82.189 & 2.515 & 7.785 & 38.6549 & 8.833 & 22.8509 \\
S-104 & 55.508 & 63.24 & 2.497 & 6.345 & 31.0555 & 7.732 & 24.8974 \\
S-105 & 58.536 & 66.376 & 2.473 & 6.94 & 33.3179 & 7.84 & 23.5309 \\
S-106 & 60.543 & 62.893 & 2.468 & 7.035 & 33.6375 & 2.35 & 6.98624 \\
S-107 & 67.169 & 76.916 & 2.537 & 7.26 & 36.6815 & 9.747 & 26.572 \\
S-108 & 66.599 & 74.517 & 2.45 & 7.415 & 34.9392 & 7.918 & 22.6622 \\
S-109 & 55.528 & 62.897 & 2.518 & 6.115 & 30.4353 & 7.369 & 24.212 \\
S-110 & 45.552 & 50.144 & 2.53 & 5.59 & 28.0881 & 4.592 & 16.3486 \\
S-111 & 53.081 & 57.592 & 2.523 & 5.2 & 25.9841 & 4.511 & 17.3606 \\
S-112 & 55.189 & 61.394 & 2.498 & 5.785 & 28.3373 & 6.205 & 21.897 \\
S-113 & 67.901 & 76.304 & 2.55 & 7.2 & 36.7521 & 8.403 & 22.864 \\
S-114 & 45.917 & 50.811 & 2.51 & 4.85 & 23.9861 & 4.894 & 20.4035 \\
S-116 & 63.095 & 71.565 & 2.5 & 6.925 & 33.9758 & 8.47 & 24.9295 \\
S-117 & 68.156 & 79.23 & 2.5 & 7.955 & 39.0292 & 11.074 & 28.3736 \\
S-118 & 59.247 & 67.823 & 2.51 & 6.625 & 32.7645 & 8.576 & 26.1747 \\
S-119 & 32.834 & 36.424 & 2.35 & 3.455 & 14.978 & 3.59 & 23.9685 \\
\hline
\end{tabular}

The pore and bulk volumes and porosity measurement was done by the following equations:

$$
\begin{aligned}
& V p=\frac{\text { Saturated weight-dry weight }}{\text { distillate water density }} \\
& V_{b}=(\pi / 4) * D^{2} * L \\
& \phi=\frac{\text { Pore Volume }}{\text { Bulk Volume }}
\end{aligned}
$$

\subsection{Liquidperm Results}

As we mentioned before the main objective of using liquidperm is for determine oil recovery only, the five different concentrations of seawater labeled as Case \#1 Case\#2 to 5 each and every one of them will take five samples, next table shows the distribution of samples.

\subsubsection{Case\#1}

The results that we have got from injection of original seawater (Case\#1) to the selected samples 103,111 and 113 can be seen in Table 6. A plot between the oil recovery and ph and salinity of Case\#1 can be seen in Figure 25 . We noticed that the RF in all three samples were generally high, the ph was avarage 7.8 and salinity was the highest 21250 ppm, and we noticed that the highest RF between the three of the samples is 111 and we think the reason is because of the low permability of the sample, on other hand the lowest RF in Case\#1 was 103 because it has the highest permability.

Table 6. Case\#1, Case\#2, Case\#3, Case\#4, and Case\#5 Results After The Injection Process

\begin{tabular}{cccccccc}
\hline CASE & $\begin{array}{c}\text { NUMBER } \\
\text { OF } \\
\text { SAMPLES }\end{array}$ & PH & $\begin{array}{c}\text { SALINITY } \\
(\mathbf{p p m})\end{array}$ & $\begin{array}{c}\text { OIL } \\
\text { VOLUME } \\
(\mathbf{c c})\end{array}$ & $\begin{array}{c}\text { PORE } \\
\text { VOLUME } \\
(\mathbf{c c})\end{array}$ & K (mD) & RF (\%) \\
\hline \multirow{2}{*}{ CASE\#1 } & 103 & \multirow{2}{*}{7.8} & 21250 & 6.892 & 8.983 & 193.395 & 76.72 \\
& 111 & & & 4.177 & 4.482 & 11.767 & 93.2
\end{tabular}




\begin{tabular}{cccccccc} 
& 113 & & & 7.125 & 8.526 & 26.386 & 83.57 \\
& 101 & & & 8.212 & 10.32 & 227.529 & 79.57 \\
CASE\#2 & 116 & \multirow{2}{*}{7.8} & \multirow{2}{*}{14000} & 8.18 & 8.66 & 118.842 & 94.4 \\
& 119 & & & 0.602 & 3.59 & 7.362 & 16.77 \\
& 107 & & & 9.29 & 9.793 & 280.827 & 94.86 \\
CASE\#3 & 117 & \multirow{2}{*}{7.8} & \multirow{2}{*}{6500} & 9.609 & 11.298 & 481.931 & 85.05 \\
& 118 & & & 7.99 & 8.358 & 308.467 & 95.6 \\
& 106 & & & 6.68 & 7.111 & 1134.011 & 93.95 \\
CASE\#4 & 108 & \multirow{2}{*}{9.98} & \multirow{2}{*}{21250} & 3 & 7.68 & 9.243 & 39.06 \\
& 109 & & & 6.75 & 6.844 & 274.341 & 98.63 \\
& 100 & & & 6.2 & 8.668 & 2.811 & 71.53 \\
CASE\#5 & 102 & \multirow{2}{*}{4.4} & \multirow{2}{*}{21250} & 8.8 & 9.032 & 430.112 & 97.43 \\
& 104 & & & 6.35 & 7.357 & 117.323 & 86.31 \\
\hline
\end{tabular}

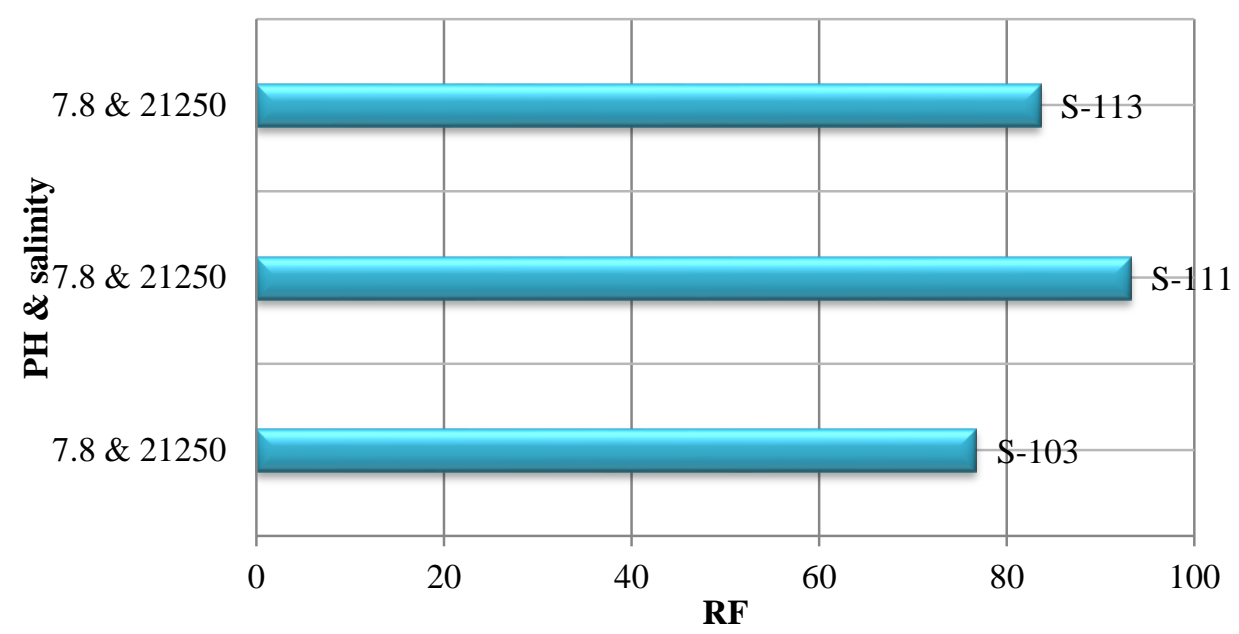

Figure 1. Case\#1 Results After The Injection Process

\subsubsection{Case\#2}

The results that we have got from injection of Case\#2 seawater (average ph \& salinity) to the selected samples 101,116 and 119 can be seen in Table 6. A plot between the oil recovery and ph and salinity of Case\#2 can be seen in Figure 26. We noticed that the RF is high in two samples which considers good and the third sample has a very low recovery and we think because of low pore volume and length of the samples which is $3 \mathrm{~cm}$ but generally the average seawater composition gives a good recovery.

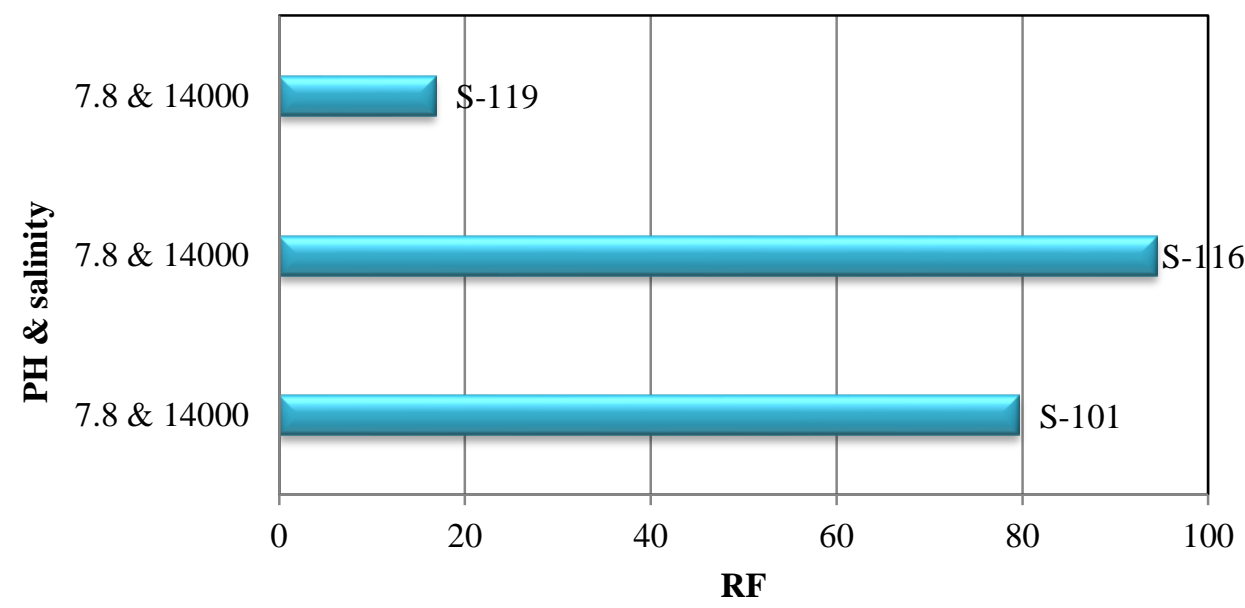

Figure 2. Case\#2 Results After The Injection Process 


\subsubsection{Case\#3}

The results that we have got from injection of Case\#3 seawater (average ph \& low salinity) to the selected samples 107,117 and 118 can be seen in Table 7. Plot between the oil recovery and ph and salinity of Case\#3 can be seen in Figure 27. We noticed that the RF is high in all samples, comparing to the previous two cases which they all have the same ph but difference salinities (high, medium, low) Case\#3 with the lowest salinity has the highest RF which indicates the low salinity gives high oil recovery.

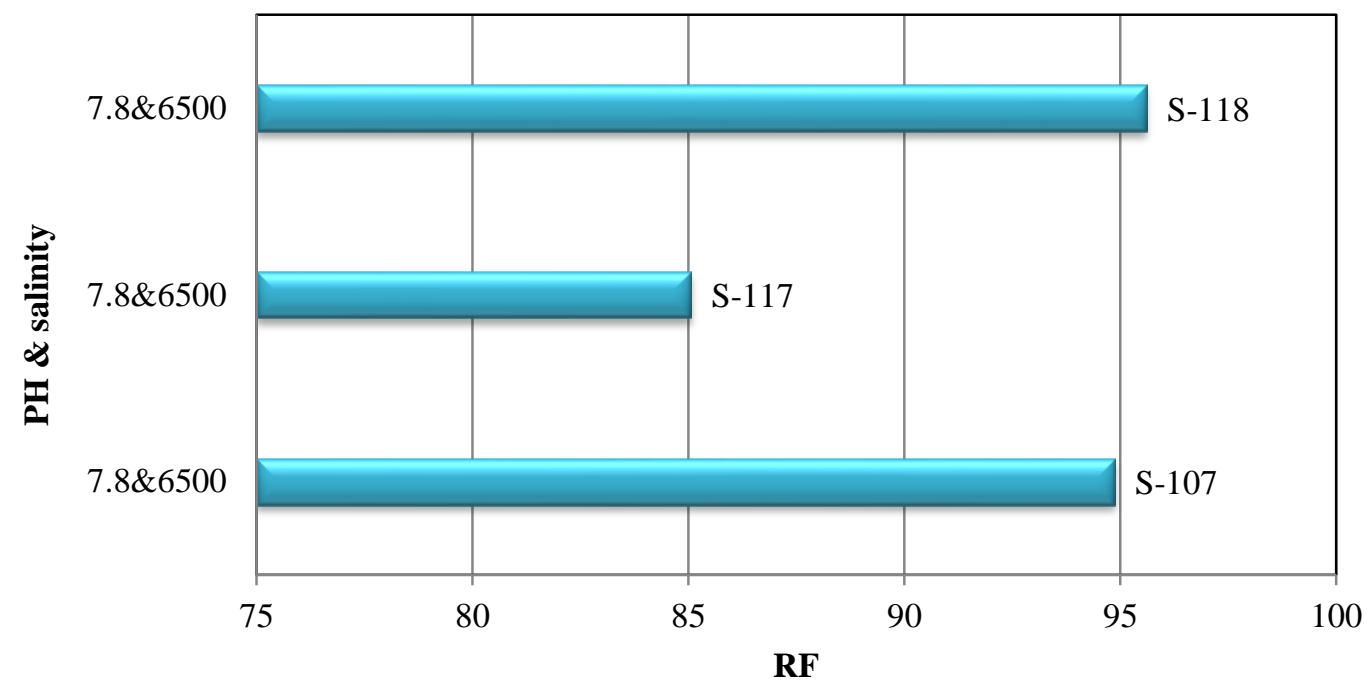

Figure 3. Case\#3 Results After The Injection Process

\subsubsection{Case\#4}

The results that we have got from injection of Case\#4 seawater (high ph \& high salinity) to the selected samples 106,108 and 109 can be seen in Table 7. A plot between the oil recovery and ph and salinity of Case\#4 can be seen in Figure 28. We noticed that the RF is high in two of three of the selected samples, in Case\#1 with the same salinity but with average ph we got a decent recovery but in Case\#4 with increasing ph the recovery has increased but we also think other factors might be the cause such as temperature and $\mathrm{K}$ and technical errors we might have avoid in this case.

The average time of the injection and the waiting process is 5 to 7 hours, the more than we wait the more result we can get but we made a view standard to go on such as the average time, even though the sample 108 didn't give high results 2 of 3 is considers acceptable.

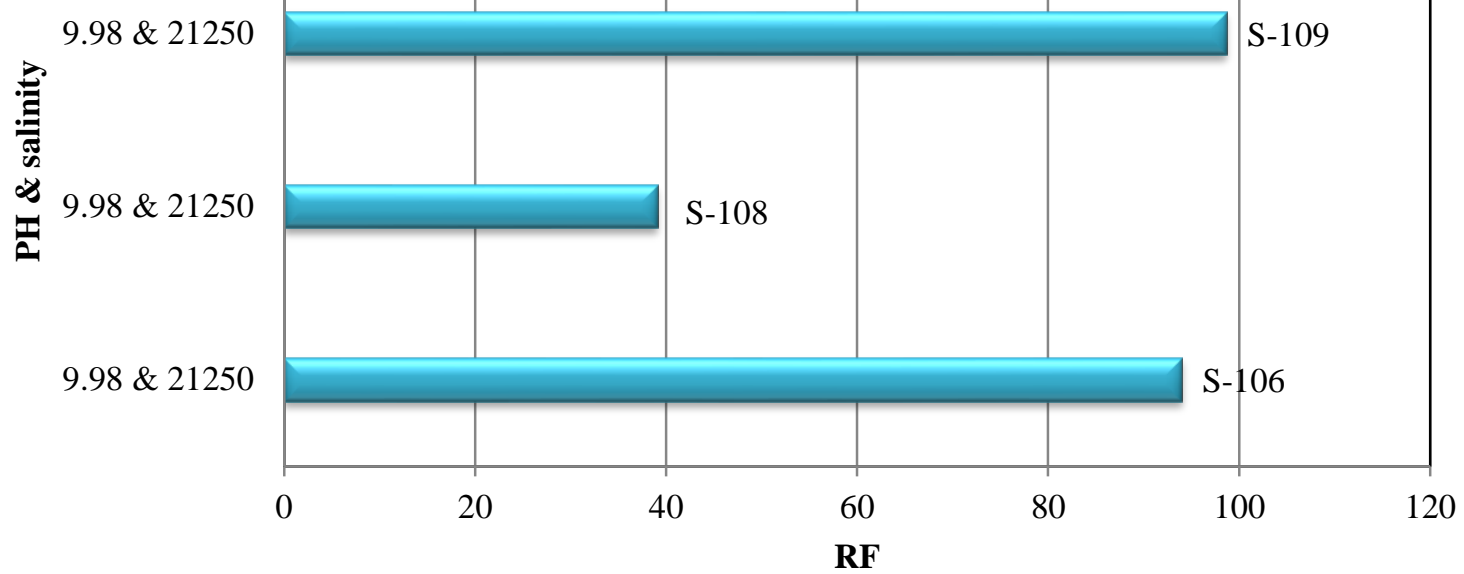

Figure 4. Case\#4 Results After The Injection Process 


\subsubsection{Case\#5}

The results that we have got from injection of Case\#5 seawater (low ph \& high salinity) to the selected samples 106,108 and 109 can be seen in Table 6. A plot between the oil recovery and ph and salinity of Case\#4 can be seen in Figure 29. We noticed that the RF is generally high in all three samples the same as Case\# 1 which have the same salinity but higher ph 7.8 which indicates that salinity under the average wouldn't have much impact on recovery.

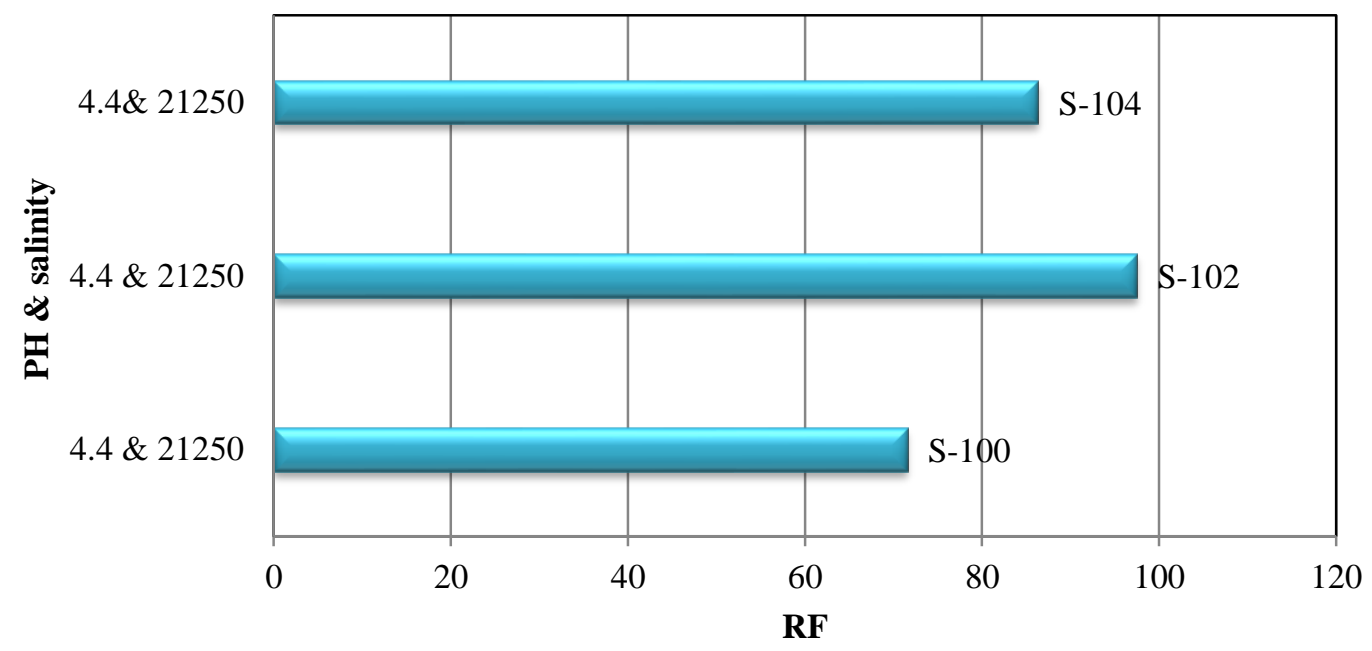

Figure 5. Case\#5 Results After The Injection Process

\section{CONCLUSION}

An experimental investigation the optimum of salinity and $\mathrm{Ph}$ of sea-water to improve oil recovery from sandstone reservoir as a secondary recovery process were presented in this paper mainly focusing on sandstone reservoir. The general conclusions and recommendations can be drawn as follows:

1. When the concentration of ph is average (7.8) and the salinity is the lowest $(6500 \mathrm{ppm})$ we got the optimum oil recovery. Ph has a small impact on oil recovery when it's less than the average (7)

2. Increasing the temperature increases the oil recovery and the flow rate $\mathrm{Q}$, which indicate that the temperature increases due the effect of oil recovery.

3. Most of the samples with high permabilities have high oil recovery. The longest the injection process lasts the highest oil recovery we can get.

4. We noticed that the most of oil were recovered at low pressures and the high pressures did not have any mentionable valuable results

5. Dean stark device needs an extra safeness and monitoring starting with air condition due to toxic material such as toluene and its flammability, the device cannot be left operating without supervision.

6. It is recommended to leave the samples in oven for at least three days and weighting them in those days until there is no change in weight.

7. The more than we leave the samples in manual saturator the more than the saturation is accurate.

8. It is preferable to adjust or makeover the samples with broken edges to fit the Liquidperm device and the injection through the pores are at the same time.

9. The confining pressure in liquidperm device should not exceed 400 psi or the sample might get fractures and some even broken into pieces.

10. The elastomeric membrane sleeve that hold the samples in the sample loading in Liquidperm device might stretch due to heating and that leads to inefficiency of confining pressure so its recommended to be replaced if such inefficiency has been noticed .

11. The outlet tube of Liquidperm device must be tighten good otherwise the confining pressure might leak.

12. The shorter the outlet tube is the more accurate result we can get.

13. It is recommended to be no airflows in the weighting process due to the sensitivity of balance.

14. Heating the oil before injection make the injection process easy and to avoid the adhesion of oil droplets that may be stuck on the wall of the tube.

15. After every injection, process the seawater must be cleaned perfectly from the equipment especially the ones in pores to avoid corrosions of the equipment. 


\section{REFERENCES}

Appelo, C. A. J. (1994). Cation and proton exchange, pH variations, and carbonate reactions in a freshening aquifer. Water Resources Research, 30(10), 2793-2805.

Austad, T., RezaeiDoust, A., \& Puntervold, T. (2010). Chemical mechanism of low salinity water flooding in sandstone reservoirs. SPE Improved Oil Recovery Symposium.

Brian, N. (2007). Handbook of valves and actuators. Roles \& Associates Ltd, UK, 82-93.

Elsharafi, M. O. (2018). Literature Review of Water Alternation Gas Injection. Journal Of Earth Energy Engineering, $7(2), 33-45$.

Griffioen, J. (1993). Multicomponent cation exchange including alkalinization/acidification following flow through sandy sediment. Water Resources Research, 29(9), 3005-3019.

Hughes, R. V, \& Pfister, R. J. (1947). Advantages of brines in secondary recovery of petroleum by water-flooding. Transactions of the AIME, 170(01), 187-201.

Jerauld, G. R., Webb, K. J., Lin, C.-Y., \& Seccombe, J. (2006). Modeling low-salinity waterflooding. SPE Annual Technical Conference and Exhibition.

Lager, A., Webb, K. J., Collins, I. R., \& Richmond, D. M. (2008). LoSal enhanced oil recovery: Evidence of enhanced oil recovery at the reservoir scale. SPE Symposium on Improved Oil Recovery.

Madsen, L., \& Ida, L. (1998). Adsorption of carboxylic acids on reservoir minerals from organic and aqueous phase. SPE Reservoir Evaluation \& Engineering, 1(01), 47-51.

RezaeiDoust, A., Puntervold, T., \& Austad, T. (2011). Chemical verification of the EOR mechanism by using low saline/smart water in sandstone. Energy \& Fuels, 25(5), 2151-2162.

Romanuka, J., Hofman, J., Ligthelm, D. J., Suijkerbuijk, B., Marcelis, F., Oedai, S., Brussee, N., van der Linde, H., Aksulu, H., \& Austad, T. (2012). Low salinity EOR in carbonates. SPE Improved Oil Recovery Symposium.

Sharma, M. M., \& Filoco, P. R. (2000). Effect of brine salinity and crude-oil properties on oil recovery and residual saturations. Spe Journal, 5(03), 293-300.

Tang, G. Q., \& Morrow, N. R. (1996). Effect of temperature, salinity and oil composition on wetting behavior and oil recovery by waterflooding. Society of Petroleum Engineers (SPE). Inc., Richardson, TX (United States). 